\title{
Creatinine-based GFR-estimating equations in children with overweight and obesity
}

\author{
Mark J. C. M. van Dam ${ }^{1} \cdot$ Hans Pottel $^{2} \cdot$ Anita C. E. Vreugdenhil ${ }^{1}$
}

Received: 4 June 2021 / Revised: 20 November 2021 / Accepted: 22 November 2021 / Published online: 24 February 2022

(c) The Author(s) 2022

\begin{abstract}
Background With the increasing prevalence of childhood obesity and related development of chronic kidney disease (CKD), there is a critical need to understand how best to assess kidney function in children with obesity. Since serum creatinine (SCr) is recommended as marker of first choice for GFR estimation, we evaluated and compared creatinine-based GFR equations in children with overweight and obesity.

Methods Six hundred children with overweight and obesity (53.5\% female; mean age 12.20 \pm 3.28 years; mean BMI z-score $3.31 \pm 0.75)$ were included from the Centre for Overweight Adolescent and Children's Healthcare $(\mathrm{COACH})$.

Results Serum creatinine ( $\mathrm{SCr}$ ), normalized using Q-age polynomials obtained from reference values, results in median and mean $\mathrm{SCr} / \mathrm{Q}$ value close to "1" for all age groups, and 96.5\% of the children have a SCr/Q within the reference band [0.67-1.33], corresponding to the 2.5th and 97.5th percentile. eGFR CKiD (bedside Schwartz equation) and SchwartzLyon decreased with age, whereas eGFR EKFC and modified CKD-EPI40 showed no age-dependency, but the distribution of eGFR values was not symmetrical. eGFR CKiD under 25 (CKiDU25) demonstrated no age-dependency but major sex differences were observed. eGFR FAS age, FAS height, and adjusted-creatinine revised Lund-Malmö (LMR18) showed a relatively symmetrical distribution and no age-dependency.

Conclusions Serum creatinine ( $\mathrm{SCr}$ ) values of children with overweight and obesity are mostly within the reference range for children. Normalization of SCr using reference Q-age polynomials works very well in this cohort. After evaluation of the different equations, we suggest that FAS age, FAS height, and LMR18 are the preferred creatinine-based GFR-estimating equations in children with overweight and obesity.

Clinical trial registration.

ClinicalTrial.gov; Registration Number: NCT02091544.
\end{abstract}

Keywords Childhood obesity $\cdot$ Creatinine $\cdot$ eGFR $\cdot$ Pediatrics

$\begin{array}{ll}\text { Abbreviations } \\ S C r / Q & \begin{array}{l}\text { Serum creatinine normalized using the Q-age } \\ \text { polynomials }\end{array} \\ & \text { Number of children } \\ n & \text { Percentile }\end{array}$

Anita C. E. Vreugdenhil

a.vreugdenhil@mumc.nl

1 Centre for Overweight Adolescent and Children's Healthcare $(\mathrm{COACH})$, Department of Pediatrics, School of Nutrition and Translational Research in Metabolism (NUTRIM), Maastricht University Medical Centre +, P. Debyelaan 25, 6229 HX Maastricht, The Netherlands

2 Department of Public Health and Primary Care, KU Leuven Campus Kulak Kortrijk, Kortrijk, Belgium

\section{Introduction}

Glomerular filtration rate (GFR) estimation is essential for daily practice in (pediatric) nephrology, since direct measurement of GFR is still considered to be too invasive for routine clinical use. Estimated GFR (eGFR) equations are highly dependent on the data used for the development of the equation and incorrect use of an equation might lead to severe inaccuracy [1]. In adults with overweight and obesity, GFR-estimating equations fail in their precision to estimate GFR [2]. Given the increasing prevalence of childhood obesity, there is a need to obtain more knowledge on how best to estimate GFR in this population, both concerning research and clinical questions such as drug dosing or chronic kidney disease (CKD) classification. 
GFR-estimating equations using endogenous filtration markers (such as serum creatinine ( $\mathrm{SCr}$ ) and cystatin $\mathrm{C}$ ) are suffering from inaccuracy (bias) and imprecision (random error). When using these equations, physicians should be aware of the factors besides the GFR that influence serum concentrations of endogenous filtration markers (the "nonGFR determinants") such as dietary intake, synthesis, tubular absorption and secretion, and kidney-independent elimination [3]. In order to partly correct for these non-GFR determinants, demographic and clinical variables such as age, sex, height, and body surface area (BSA) are implemented in eGFR equations. However, these factors do not fully encompass the altered body proportions in children and adults with adiposity. Moreover, most commonly used eGFR equations were developed and validated in individuals with predominantly normal body composition [4].

Although other endogenous filtration markers are available, $\mathrm{SCr}$ is still recommended as marker of first choice for GFR evaluation. Creatinine, synthesized in the liver and kidneys, is stored predominantly in striated muscle cells [5]. The volume of distribution of creatinine is total body water [6] and it is known that $\mathrm{SCr}$ is influenced by lean body mass [7]. Besides endogenous creatinine production, dietary protein intake and creatine supplements may contribute to the serum creatinine concentration [3]. In children, $\mathrm{SCr}$ linearly increases with age between the age of 2 and 14 years and levels off to constant values of $0.90 \mathrm{mg} / \mathrm{dL}$ for adult males and $0.70 \mathrm{mg} / \mathrm{dL}$ for adult females. GFR is indexed with BSA, allowing comparison among children and adults [1, 8-11]. Although indexation of GFR for BSA for individuals with altered body proportions is a controversial topic [2, 12, 13], almost all current creatinine-based GFR-estimating equations have been designed for GFR indexed with BSA [1, 4].

The association between obesity in adulthood and incidence of CKD and CKD progression is currently well established [14] and there is some evidence of an association between childhood obesity and CKD later in life [15]. This, combined with the increasing prevalence of childhood obesity, underlines the need to understand how best to assess kidney function in children with obesity. Therefore, we evaluated $\mathrm{SCr}$ and creatinine-based GFR-estimating equations in children with overweight and obesity.

\section{Methods}

\section{Setting and study inclusion}

For this study, baseline data were used from participants of the Centre for Overweight Adolescent and Children's Healthcare $(\mathrm{COACH})$ at the Maastricht University Medical Centre $+(\mathrm{MUMC}+)$. $\mathrm{COACH}$ is a multidisciplinary lifestyle program in which the health status of children with overweight and obesity is evaluated, as described previously [16]. Children who enter the $\mathrm{COACH}$ program are evaluated thoroughly in order to examine possible secondary causes of overweight and obesity and obesity-associated comorbidities. This first evaluation includes history taking, clinical examination and laboratory tests among others. All 662 participants who entered the COACH program between January 1, 2011, and April 1, 2019, were considered for inclusion in this study. Children with secondary causes of overweight, a history of (congenital or acquired) kidney disease that was known before inclusion into our program, diabetes mellitus, and/or current use of antihypertensive medication were excluded from this study $(n=13)$. Moreover, in 39 children the value for serum creatinine (SCr) was missing. Five children did not meet the criteria for overweight or obesity and 5 children were older than 18 years and were thus excluded from this study. Overall, 600 children were included in this study. The study met the guidelines administered by the Declaration of Helsinki and was approved by the Medical Ethical Committee of the MUMC + . Informed consent was obtained from all parents or legal guardians and children, provided they were 12 years or older.

\section{Clinical assessment and anthropometry}

All children underwent a physical examination. Weight and height were determined using a digital scale (Seca, Chino, CA) and digital stadiometer (De Grood Metaaltechniek, Nijmegen, the Netherlands), respectively. The International Obesity Task Force (IOTF) criteria were used to define overweight, obesity, and severe obesity [17]. Body surface area (BSA) was calculated using height $(\mathrm{cm})$ and weight $(\mathrm{kg})$, using the Haycock et al. equation: $(\mathrm{Ht})$ $\left(B S A=0.024265 \times W t^{0.5378} \times H t^{0.3964}\right)[18]$.

\section{Creatinine-based GFR-estimating equations}

Serum creatinine ( $\mathrm{SCr}$ ) was measured using the enzymatic method (Cobas 8000, Roche), equivalent to the isotope dilution mass spectrometry (IDMS) gold standard method. Creatinine references values (median $\mathrm{SCr}$ for "healthy children," so-called Q-values) were obtained from the literature [19, 20]. These Q-values were used to calculate $\mathrm{SCr} / \mathrm{Q}$ ("normalized SCr") which is supposed to be age- and sex-independent for healthy subjects. It has been shown by Pottel et al. [21] that the reference band for $\mathrm{SCr} / \mathrm{Q}$ in children is defined by [0.67-1.33], with lower and upper limits corresponding to the 2.5th and 97.5th percentile. GFR was estimated using the following creatinine-based GFR-estimating equations, displayed in Table 1:

- Height-independent full-age spectrum equation, referred to as FAS age [22]; 
Table 1 Overview of the creatinine-based GFR-estimating equations examined in this study

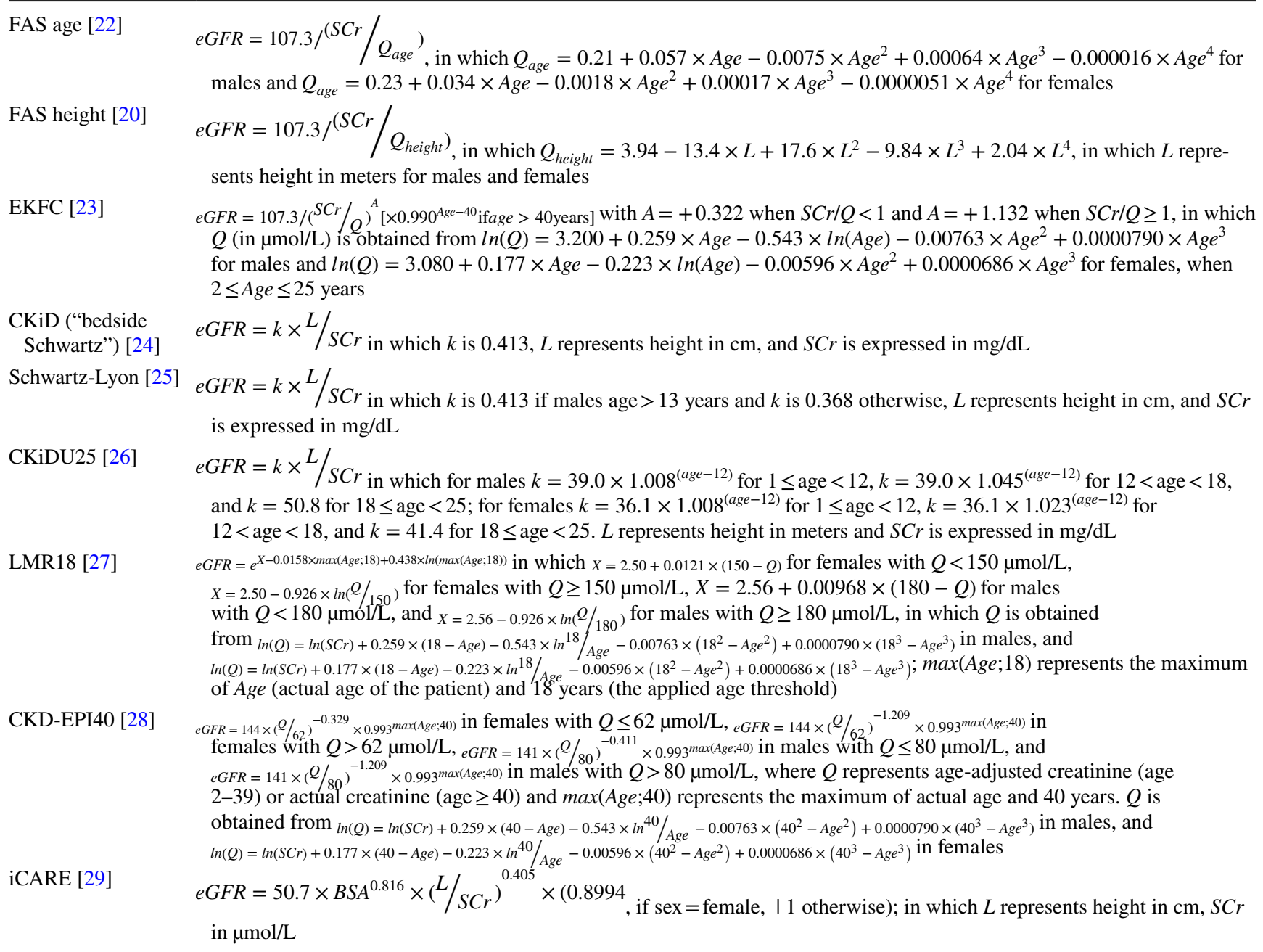

Abbreviations: $F A S$, full-age spectrum; $E K F C$, European Kidney Function Consortium; $C K i D$, Chronic Kidney Disease in Children; $C K i D U 25$, CKiD under 25; LMR18, revised Lund-Malmö extended to children; CKD-EPI40, Chronic Kidney Disease Epidemiology Collaboration extended to children; $i C A R E$, Improving renal complications in Adolescents with T2D through Research; $S C r$, serum creatinine; $B S A$, body surface area

- Height-dependent full-age spectrum equation, referred to as FAS height [20];

- The new European Kidney Function Consortium (EKFC) equation, referred to as EKFC [23];

- Updated bedside Schwartz or CKiD equation [24];

- Schwartz-Lyon equation [25];

- CKiD under 25 years equation (CKiDU25) [26];

- Adjusted-creatinine revised Lund-Malmö equation, referred to as LMR18 [27];

- CKD-EPI equation with age-adjusted creatinine values, referred to as CKD-EPI40 [28];

- Improving renal complications in Adolescents with T2D through Research equation, referred to as iCARE [29].

\section{Statistical analysis}

The basic features of the data in this study were described using descriptive statistics. Summary statistics are presented as mean \pm standard deviation (for normally distributed data) and median (interquartile range) otherwise. Minimum, maximum, and percentiles (P5, P25, P75, and P95) are presented for $\mathrm{SCr} / \mathrm{Q}$. Distributions of $\mathrm{SCr} / \mathrm{Q}$ and eGFR predictions are presented as histograms and quantile regression is used to investigate the age-dependency of $\mathrm{SCr} / \mathrm{Q}$ and eGFR predictions. Generalized linear models were used for $\mathrm{SCr} / \mathrm{Q}$ and all GFR-estimating equations with age (2-year subgroups), sex, 
IOTF, and their interactions. All statistics were performed with SAS 9.4 (SAS Institute Inc., Cary, NC, USA). Clinical trial registration: ClinicalTrial.gov; Registration Number: NCT02091544.

\section{Results}

\section{Characteristics}

Six hundred children were included in this study of whom $53.5 \%$ were female. Mean age was $12.20 \pm 3.28$ years. Mean BMI z-score was $3.31 \pm 0.75$ and the prevalence of overweight, obesity, and severe obesity was $21.3 \%, 44.7 \%$, and $34.0 \%$, respectively. Mean BSA was $1.78 \pm 0.43 \mathrm{~m}^{2}$.

\section{Creatinine values for age}

In Fig. 1, SCr is plotted against age for males and females, in which the band represents the reference interval for $\mathrm{SCr}$ based on the Hoste polynomials [20]. From Fig. 1, it can be concluded that most of the children have $\mathrm{SCr}$ values lying within the reference band. Moreover, there is a slight difference between the bands for males and females, especially for ages $>15$ years. In Fig. 2, SCr/Q ("normalized SCr") is plotted against age with the reference band [0.67-1.33] as described by Pottel et al. [21]. 96.5\% of the children have a $\mathrm{SCr} / \mathrm{Q}$ within this reference band. There are some children with $\mathrm{SCr} / \mathrm{Q}>1.33$, but they all have $\mathrm{SCr} / \mathrm{Q} \leq 1.5$. There is 1 child with a very low $\mathrm{SCr} / \mathrm{Q}$ value (a boy aged 17 years and 9 months with a SCr/Q value of 0.43 ). Normalizing SCr with the Q-values results in data presented in Table 2. Except for the [0-4] year age group (with only 3 subjects), the median and mean $\mathrm{SCr} / \mathrm{Q}$ is close to " 1 " for all age groups. In general,

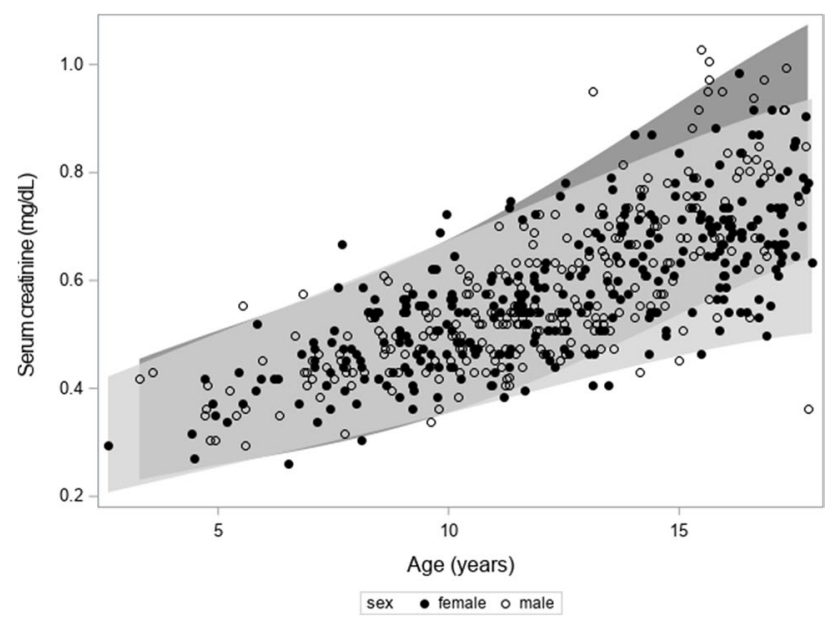

Fig. 1 Serum creatinine ( $\mathrm{SCr}$, in $\mathrm{mg} / \mathrm{dL}$ ) against age for males and females. The band represents the reference interval for $\mathrm{SCr}$ based on the Hoste polynomials [20] there is a small but significant difference between males and females ( 0.97 vs. 1.01$)$ in mean normalized $\operatorname{SCr}(p=0.0006)$. As the standard deviation in each subgroup is stable, it can be expected that the $\mathrm{SCr} / \mathrm{Q}$ values are normally distributed, which is shown in Fig. 3. The linear quantile regression in the same figure shows a flat median quantile line close to " 1 ."

\section{Creatinine-based GFR-estimating equations}

Knowing that the $\mathrm{SCr}$ values are within the reference range for age and sex for corresponding healthy children, it would be expected that eGFR is age- and sex-independent. In Fig. 4, histograms and linear quantile regression lines for percentiles 2.5, 50, and 97.5 are presented for the creatinine-based GFR-estimating equations.

\section{eGFR FAS age (Fig. 4a)}

It is important to note that when $\mathrm{SCr} / \mathrm{Q}$ is normally distributed, and FAS age was defined as 107.3/(SCr/Q), thus inversely related to $\mathrm{SCr} / \mathrm{Q}$, then it is mathematically impossible that FAS age is normally distributed. The distribution will be skewed to the right. However, in the literature, it has never been shown that measured GFR shows a distribution skewed to the right. Therefore, this is an artifact of the FAS equation, and this artifact is especially pronounced when SCr/Q is very low. The outlier of 0.43 can be seen as the outlier of $107.3 / 0.43=250 \mathrm{~mL} / \mathrm{min} / 1.73 \mathrm{~m}^{2}$ (as mentioned above). A mean of $\mathrm{SCr} / \mathrm{Q}=1$ is expected ideally, which corresponds to FAS age $=107.3 \mathrm{~mL} / \mathrm{min} / 1.73 \mathrm{~m}^{2}$. The vertical lines correspond to $107.3 / 1.33=80.67 \mathrm{~mL} / \mathrm{min} / 1.73 \mathrm{~m}^{2}$, that is, the lower limit for FAS age corresponding to the upper

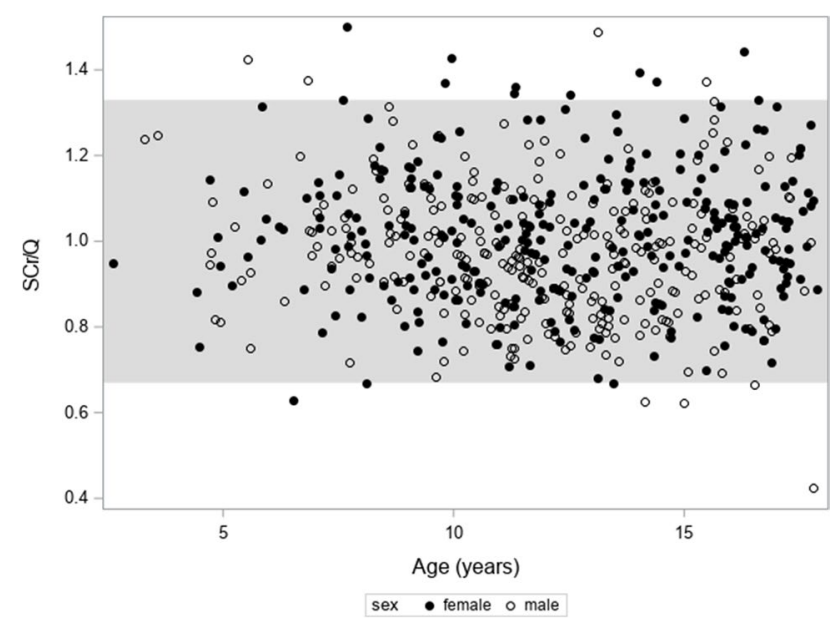

Fig. $2 \mathrm{SCr} / \mathrm{Q}$ against age with the reference band [0.67-1.33] as described by Pottel et al. [21]. 96.5\% of the children have a SCr/Q within this reference band 
Table 2 Normalized SCr with the Q-values, stratified per age category
Fig. 3 Histogram with normal density function overlaid for normalized or rescaled SCr. The vertical reference lines correspond with the lower and upper limits of 0.67 and 1.33 (left). Linear quantile regression lines for percentiles $2.5,50$, and 97.5 are shown (right)

\begin{tabular}{llllllllllll}
\hline Age (years) & $n$ & \multicolumn{1}{l}{$\mathrm{SCr} / \mathrm{Q}$} \\
\cline { 3 - 10 } & & & Mean \pm SD & Minimum & P5 & P25 & Median & P75 & P95 & Maximum & $\begin{array}{l}\text { Interquartile } \\
\text { range }\end{array}$ \\
\hline$[0-4]$ & 3 & $1.15 \pm 0.17$ & 0.95 & 0.95 & 0.95 & 1.24 & 1.25 & 1.25 & 1.25 & 0.30 \\
{$[4-6]$} & 22 & $1.00 \pm 0.17$ & 0.75 & 0.76 & 0.90 & 0.97 & 1.09 & 1.32 & 1.42 & 0.20 \\
{$[6-8]$} & 45 & $1.02 \pm 0.15$ & 0.63 & 0.79 & 0.94 & 1.02 & 1.07 & 1.33 & 1.50 & 0.12 \\
{$[8-10]$} & 84 & $1.03 \pm 0.16$ & 0.67 & 0.77 & 0.91 & 1.02 & 1.14 & 1.28 & 1.43 & 0.23 \\
{$[10-12]$} & 136 & $0.97 \pm 0.14$ & 0.71 & 0.75 & 0.87 & 0.96 & 1.06 & 1.24 & 1.36 & 0.18 \\
{$[12-14]$} & 109 & $0.96 \pm 0.16$ & 0.67 & 0.75 & 0.84 & 0.94 & 1.07 & 1.24 & 1.49 & 0.23 \\
{$[14-16]$} & 112 & $0.99 \pm 0.16$ & 0.62 & 0.73 & 0.88 & 0.99 & 1.09 & 1.29 & 1.39 & 0.22 \\
{$[16-18]$} & 89 & $1.00 \pm 0.16$ & 0.43 & 0.77 & 0.91 & 1.01 & 1.09 & 1.26 & 1.44 & 0.17 \\
\hline
\end{tabular}
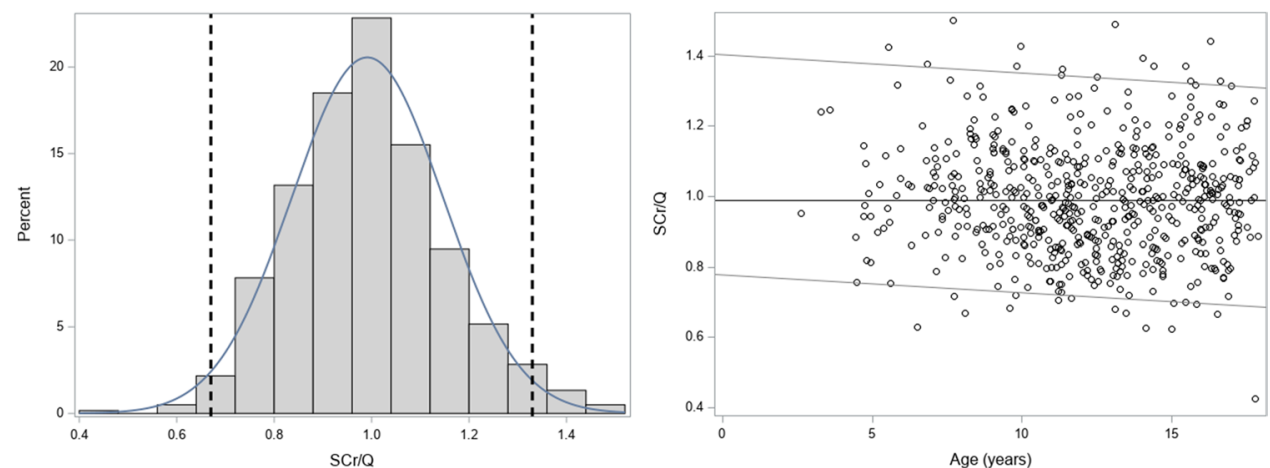

limit of 1.33 for $\mathrm{SCr} / \mathrm{Q}$. Symmetrical to the lower limit of $80.67 \mathrm{~mL} / \mathrm{min} / 1.73 \mathrm{~m}^{2}, 134 \mathrm{~mL} / \mathrm{min} / 1.73 \mathrm{~m}^{2}$ was defined as the (possible) symmetrical upper limit for FAS age. However, when $\mathrm{SCr} / \mathrm{Q}=0.67$ (the lower limit for rescaled creatinine) was used, then an upper limit for FAS age of $160 \mathrm{~mL} / \mathrm{min} / 1.73 \mathrm{~m}^{2}$ was found. There is a small but significant difference in eGFR between males and females (113.8 vs. $108.6 \mathrm{~mL} / \mathrm{min} / 1.73 \mathrm{~m}^{2}, p=0.0006$ ).

\section{eGFR FAS height (Fig. 4b)}

Median values are shifted to higher values, compared with FAS age, while the extreme outlier is less outlying. This means that higher Q-values are used in the FAS height equation compared to the FAS age equation. There is a small but significant difference in eGFR between males and females (118.6 vs. $\left.113.4 \mathrm{~mL} / \mathrm{min} / 1.73 \mathrm{~m}^{2}, p=0.0021\right)$.

\section{eGFR EKFC (Fig. 4c)}

The EKFC equation is a modified (or optimized) FAS equation, which addresses the flaw of the FAS equation of large overestimation when $\mathrm{SCr} / \mathrm{Q}$ values are low. Median values may not be affected, but the high eGFR predictions by FAS will not be present when EKFC is used. The distribution is narrower and appears to be skewed to the left (as a consequence of the new power coefficients in the EKFC equation). There is a significant difference in eGFR between males and females (106.8 vs. $\left.101.4 \mathrm{~mL} / \mathrm{min} / 1.73 \mathrm{~m}^{2}, p<0.0001\right)$.

\section{eGFR bedside Schwartz or CKiD (Fig. 4d)}

The histogram is relatively symmetrical, although slightly skewed to the right. The age-dependent decline is probably an artifact of the Schwartz-equation in children without CKD, due to using a fixed $k$ value of 0.413 throughout the entire age range of 2-18 years. This age-dependency of the CKiD (and the Schwartz-Lyon) equation is not unique to our population, as it can also be observed when applying metadata from healthy children in Belgium [1] to these equations (Supplementary Information). This decline with age is even more pronounced in male adolescents. There is no significant difference in eGFR between females and males (112.4 vs. $115.2 \mathrm{~mL} / \mathrm{min} / 1.73 \mathrm{~m}^{2}, p=0.0858$ ).

\section{eGFR Schwartz-Lyon (Fig. 4e)}

This equation is very similar to the CKiD equation, but differs for females and pre-pubertal males. The same decrease in 

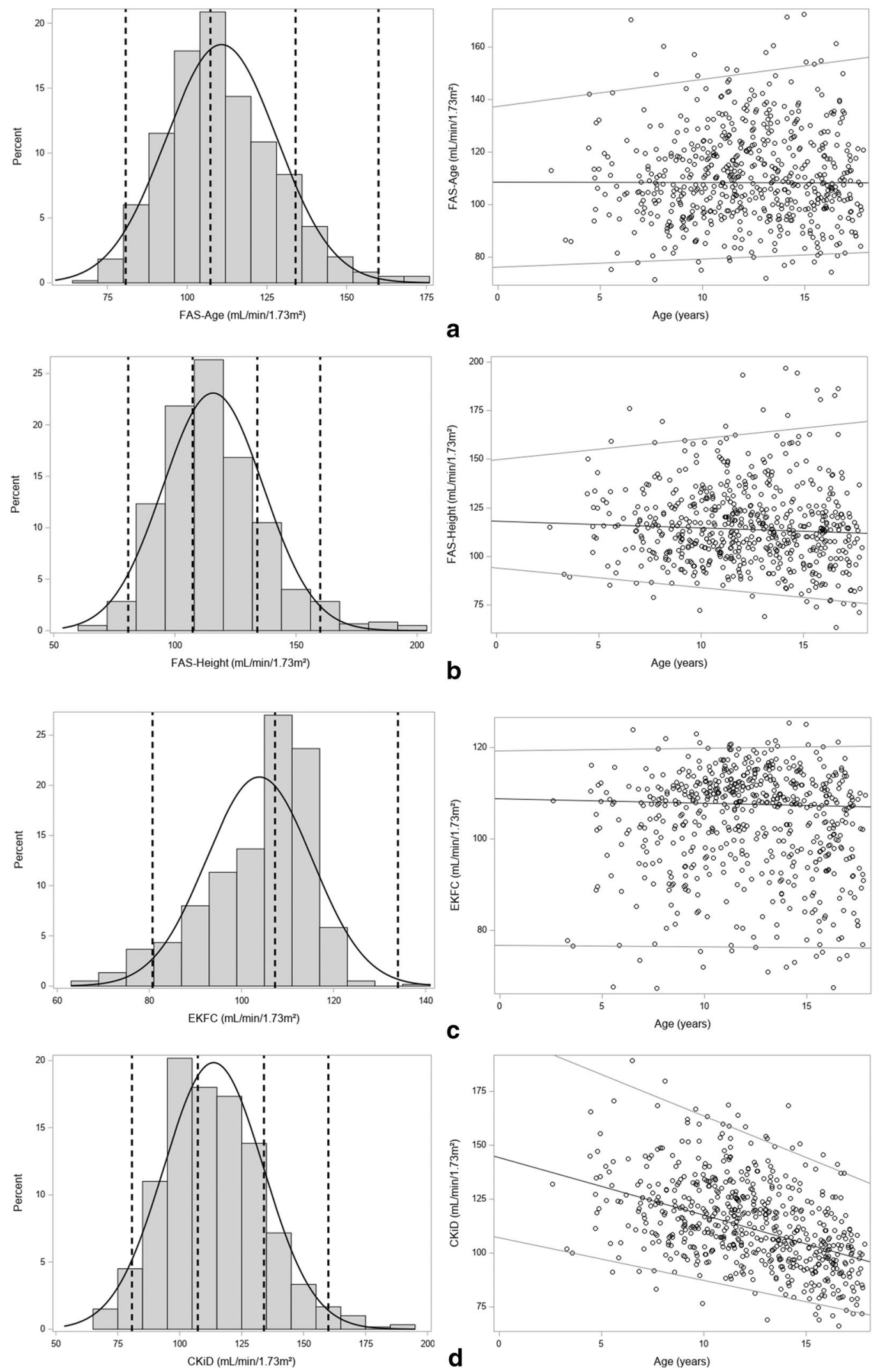

Fig. 4 Histograms and linear quantile regression of eGFR FAS age (a); FAS height (b); EKFC (c); CKiD (bedside Schwartz) (d); Schwartz-Lyon (e); CKiDU25 (f); LMR18 (g); CKD-EPI40 (h). The vertical lines in the histograms correspond to 80.7 (lower

limit), 107.3 (median), 133.9 (=symmetrical to 80.7), and 160.1 (upper limit) corresponding to the FAS-eGFR limits calculated from $\mathrm{SCr} / \mathrm{Q}=0.67,1$, and 1.33 as defined by Pottel et al. [21] 

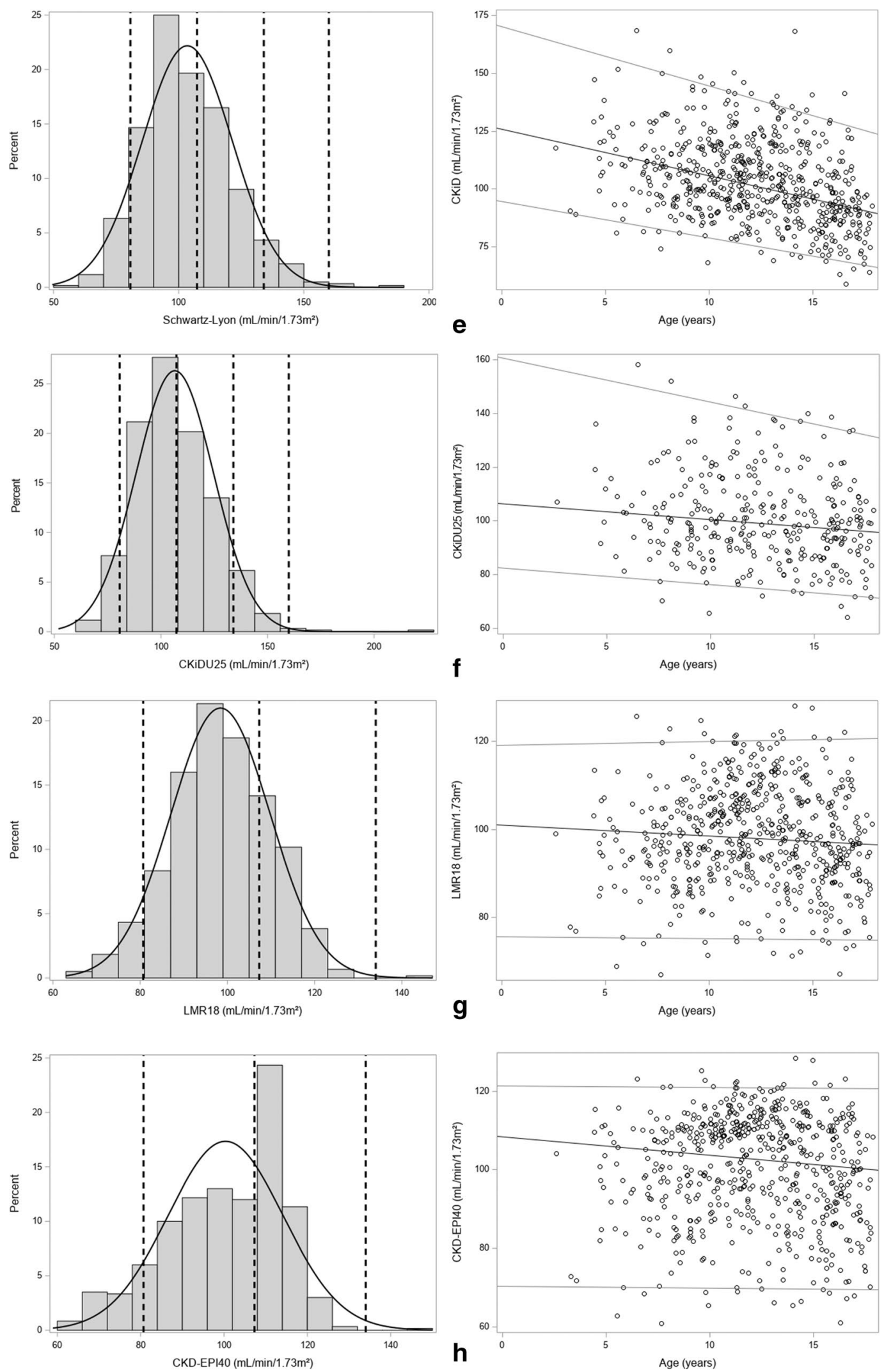

Fig. 4 (continued) 
eGFR is observed as for the eGFR bedside Schwartz equation. Median eGFR value is about $125 \mathrm{~mL} / \mathrm{min} / 1.73 \mathrm{~m}^{2}$ at 2 years of age and decreases to about $90 \mathrm{~mL} / \mathrm{min} / 1.73 \mathrm{~m}^{2}$ at 18 years. There is a significant difference in eGFR between males and females (107.2 vs. $\left.100.1 \mathrm{~mL} / \mathrm{min} / 1.73 \mathrm{~m}^{2}, p<0.0001\right)$.

\section{eGFR CKiDU25 (Fig. 4f)}

This recently updated $\mathrm{CKiD}$ equation no longer showed the decline with age, as a consequence of using age- and sexdependent $k$ values. None of the slopes of the quantile lines was significantly different than zero, when studied separately in males and females. In other words, the CKiDU25 equation does not show an age-dependency in our cohort. However, there is a large difference in eGFR between males and females across the entire age spectrum: the mean eGFR is $100.8 \mathrm{~mL} / \mathrm{min} / 1.73 \mathrm{~m}^{2}$ for females and $113.2 \mathrm{~mL} / \mathrm{min} / 1.73 \mathrm{~m}^{2}$ for males $(p<0.0001)$. eGFR values using this CKiDU25 are lower compared to the CKiD equation, especially in children below 10 years of age.

\section{eGFR LMR18 (Fig. 4g)}

The histogram is relatively symmetrical and the linear quantile regression lines are flat, indicating that there is no age-dependency. There is a significant difference in eGFR between males and females (101.9 vs. $\left.95.4 \mathrm{~mL} / \mathrm{min} / 1.73 \mathrm{~m}^{2}, p<0.0001\right)$.

\section{eGFR CKD-EPI40 for children (Fig. 4h)}

This modified CKD-EPI equation does not show an agedependency, but the distribution of eGFR values is not symmetrical. There is a significant difference in eGFR between males and females (104.7 vs. $\left.96.6 \mathrm{~mL} / \mathrm{min} / 1.73 \mathrm{~m}^{2}, p<0.0001\right)$.

\section{eGFR iCARE}

As a result of the BSA correction in this equation, eGFR iCARE increases with age which stabilizes after age 12. In other words, iCARE cannot be used in children aged 12 years and younger, but seems applicable for adolescents with overweight and obesity. It is remarkable that iCARE predicts really high eGFR values for the adolescent group (which it is designed for). No other equation predicts values this high. There is a significant difference in eGFR between males and females (127.7 vs. $\left.113.4 \mathrm{~mL} / \mathrm{min} / 1.73 \mathrm{~m}^{2}, p<0.0001\right)$.

\section{Age- and sex-dependency of the creatinine-based GFR-estimating equations}

When comparing the young age group (12 years and younger) with the older age group (older than 12 years) in females and males, there was no consistency in the results of the different equations. Briefly, we observed a strong age-decline in CKiD and Schwartz-Lyon, but not in the other equations. Most equations showed small differences between sexes, but CKiD and Schwartz-Lyon show no differences between males and females in young children, but substantial differences in adolescents. CKiDU25 shows systematic differences between males and females over the entire age range. Detailed analyses of the ageand sex-dependency of the creatinine-based GFR-estimating equations can be found in the Supplementary Information.

\section{Creatinine-based GFR-estimating equations and IOTF criteria}

In order to examine possible effects of the different IOTF classes (overweight, obesity, and severe obesity) on $\mathrm{SCr} / \mathrm{Q}$ and the different SCr-based GFR-estimating equations, generalized linear models were made for $\mathrm{SCr} / \mathrm{Q}$ and all GFR-estimating equations (as the dependent variable) with age (2-year subgroups), sex, IOTF, and their interactions (as independent variables). SCr/Q was not affected by age and sex (as supposed), nor by IOTF and their interactions. The height-dependent equations (FAS height, CKiD, Schwartz-Lyon, and CKiDU25) demonstrated a minor but significant IOTF dependency, with slightly higher eGFR values in children with obesity and severe obesity compared to children with overweight. The agedependent equations (FAS age, EKFC, LMR18, and CKDEPI40) did not show an IOTF dependency.

\section{Discussion}

The main message from this study is that serum creatinine ( $\mathrm{SCr}$ ) values of children with overweight and obesity were mostly within the reference range. Q-age polynomials (the median SCr for healthy children and adolescents) from reference values [20] can be used to normalize serum creatinine ("SCr/Q") in our cohort, resulting in a value that is age- and sex-independent, evidenced by a median and mean SCr/Q close to " 1 " for all age groups. As $96.5 \%$ of the children with overweight and obesity in this study have a SCr/Q within the reference interval [0.67-1.33] [21], this reference interval can be used to evaluate the normality (or abnormality) of normalized $\mathrm{SCr}$ in children with overweight and obesity without overt kidney disease.

Creatinine is the most commonly used endogenous marker for kidney function in children and adults [3]. Until approximately two decades ago, reference values for $\mathrm{SCr}$ varied between hospitals. Since the implementation of isotope dilution mass spectroscopy (IDMS)-based calibration of creatinine measurement, reference values for $\mathrm{SCr}$ in the pediatric population are uniform over the entire age spectrum $[19,30]$. Normal values for $\mathrm{SCr}$ are heavily age-dependent, as $\mathrm{SCr}$ increases with muscle mass and (thus) age, with the 
exception of the neonatal period. Until the age of 14 years, there is no sex-specific difference in $\mathrm{SCr}$, while from the age of 14 years, normal values of $\mathrm{SCr}$ in male adolescents are higher than in females [19]. Children with overweight and obesity are taller and have an increased absolute fat mass (FM) and fat-free mass (FFM) compared to age- and sexmatched normal weight children; approximately $75 \%$ of the excess weight is FM, the remainder FFM [31]. Based on this, one should expect higher $\mathrm{SCr}$ values in children with overweight and obesity compared to lean children. We here showed that $\mathrm{SCr}$ values of children with overweight and obesity are within the reference range. While some studies have demonstrated similar $\mathrm{SCr}$ values between children with lean weight and overweight or obesity [32-35], in other studies $[36,37], \mathrm{SCr}$ values were higher in children with overweight or obesity compared to lean controls. It is not excluded that these inconsistent results are due to confounding factors such as age, height, and sex and/or due to the heterogeneity of the methods for $\mathrm{SCr}$ measurements. Finally, $\mathrm{SCr}$ reference values are derived from healthy individuals $[19,30]$. In both reference studies, anthropometry or body proportion was not mentioned, and therefore, the prevalence of overweight or obesity is not known. It is therefore conceivable that $\mathrm{SCr}$ reference values are different, possibly lower, in a cohort of exclusively normal weight children.

Since $\mathrm{SCr}$ in our cohort is within the reference range for children, and we did not observe an age- and sex-dependency of SCr, it is not expected to see abnormal kidney function; hence, one can expect normal GFR (in $\mathrm{ml} / \mathrm{min} / 1.73$ $\mathrm{m}^{2}$ ) and no age/sex-dependency. Also, it is known that measured GFR is stable between 2 and 40 years of age, around $100-110 \mathrm{~mL} / \mathrm{min} / 1.73 \mathrm{~m}^{2}$. Combining these 2 arguments, it was expected to see a flat and sex-independent GFR age relationship for the median and for the quantiles. This is clearly not the case for the CKiD (bedside Schwartz) [24] and Schwartz-Lyon equation [25] which show a decreasing eGFR age pattern. This age-dependency of the CKiD and Schwartz-Lyon equation is not unique to our population, as it can also be observed when applying metadata from healthy children in Belgium [1] to these equations (Supplementary Information). It can therefore be concluded that these equations, that were developed using data from growth-retarded children with CKD, are not suitable for children of normal height without CKD, with and without overweight and (severe) obesity. The CKiDU25 equation [26] overcomes the age-dependency by using age- and sex-dependent $k$ values. However, in our cohort, this equation exhibits a large difference in eGFR between males and females over the entire age spectrum. This sex difference deviates from what is observed with other equations and from what is observed in healthy males and females. On the other hand, the iCARE equation [29] shows an increasing eGFR age pattern. As a result of the BSA correction in this equation, eGFR iCARE increases with age which stabilizes after age 12 . In other words, iCARE cannot be used in children 12 years old and younger, but seems applicable for adolescents with overweight and obesity. However, it should be mentioned that iCARE predicts very different values for adolescent males and females (a difference of $15 \mathrm{~mL} / \mathrm{min} / 1.73 \mathrm{~m}^{2}$ ) and $25-30 \%$ higher values compared to the other equations. It should be noted that the iCARE equation was designed for children with overweight/obesity and type 2 diabetes mellitus, but these large differences require further investigation and the need for measured GFR. FAS age [22], FAS height [20], and LMR18 [27] equations show a relatively symmetrical distribution and no age-dependency. The EKFC [23] and CKD-EPI40 formulas [28] also do not show an age-dependency, but the distribution of eGFR values is not symmetrical. There is no consistency between the equations regarding the differences between males and females in young and adolescent age groups. Finally, the height-dependent equations (FAS height, CKiD, Schwartz-Lyon, and CKiDU25) indicate a minor but statistically significant higher eGFR in children with obesity and severe obesity, compared to children with overweight. The age-dependent equations (FAS age, EKFC, LMR18, and CKD-EPI) do not show such a dependency. Considering all of this, we suggest that eGFR FAS age, FAS height, and LMR18 can be allotted as the preferred eGFR equations in children with overweight and obesity.

This study is not without limitations. First and most important, it lacks a gold standard measurement of GFR. It is therefore impossible to state whether the preferred creatinine-based GFR-estimating equation can reflect real kidney function in children with overweight and obesity. In adults with overweight and obesity, the random error of creatinine-based GFR-estimating equations is wide; $90 \%$ of the estimations had an error within $\pm 55 \%$ of measured GFR, determined using plasma iohexol disappearance [2]. Another limitation of this study is the lack of another endogenous marker for kidney function, such as cystatin $\mathrm{C}$. Where creatinine heavily depends on muscle mass, this does not apply to cystatin C [38]. However, cystatin C synthesis is upregulated in adipose tissue in case of obesity [39] and cystatin C does not improve reliability of GFR estimation over $\mathrm{SCr}$ in adults with overweight and obesity [2]. However, there are studies in children in which cystatin $\mathrm{C}$ improves the predictive performance of eGFR equations [3]. Finally, an approach in which $\mathrm{SCr}$ - and cystatin C-based eGFR are compared, instead of combined into more complex equations, can add confidence to the accuracy of the GFR [40] and can have additional advantages as well [3].

Therefore, we suggest that future research implement other endogenous markers for kidney function, such as cystatin $\mathrm{C}$ and measured GFR in order to examine the role of GFR-estimating equations in children with overweight and obesity. It is possible that such studies could also contribute 
to our understanding of whether GFR-indexation with BSA, or de-indexation of eGFR is helpful in children with overweight and obesity, a topic that is controversial in individuals with altered body proportions $[12,41]$.

In conclusion, $\mathrm{SCr}$ values of children with overweight and obesity without overt kidney disease are mostly within the reference range. Normalization of SCr using reference Q-age polynomials works very well in this cohort. After evaluation of the different equations, we suggest that FAS age, FAS height, and LMR18 are the preferred creatininebased GFR-estimating equations in children with overweight and obesity.

Supplementary Information The online version contains supplementary material available at https://doi.org/10.1007/s00467-021-05396-y.

Acknowledgements The authors thank all participating children and their parents, as well as the members of the treatment team for their commitment and contribution to the Centre for Overweight Adolescent and Children's Healthcare (COACH).

Author contribution All authors contributed to the study conception and design. Material preparation, data collection, and analysis were performed by Mark J.C.M. van Dam and Hans Pottel. The first draft of the manuscript was written by Mark J.C.M. van Dam and all authors commented on previous versions of the manuscript. All authors read and approved the final manuscript.

Data availability The datasets generated during and/or analyzed during the current study are available from the corresponding author on reasonable request due to privacy and other restrictions.

Code availability Not applicable.

\section{Declarations}

Conflict of interest The authors declare no competing interests.

Open Access This article is licensed under a Creative Commons Attribution 4.0 International License, which permits use, sharing, adaptation, distribution and reproduction in any medium or format, as long as you give appropriate credit to the original author(s) and the source, provide a link to the Creative Commons licence, and indicate if changes were made. The images or other third party material in this article are included in the article's Creative Commons licence, unless indicated otherwise in a credit line to the material. If material is not included in the article's Creative Commons licence and your intended use is not permitted by statutory regulation or exceeds the permitted use, you will need to obtain permission directly from the copyright holder. To view a copy of this licence, visit http://creativecommons.org/licenses/by/4.0/.

\section{References}

1. Pottel H (2017) Measuring and estimating glomerular filtration rate in children. Pediatr Nephrol 32:249-263

2. López-Martínez M, Luis-Lima S, Morales E, Navarro-Díaz M, Negrín-Mena N, Folgueras T, Escamilla B, Estupiñán S, Delgado-Mallén P, Marrero-Miranda D, González-Rinne A, MiquelRodríguez RM, Cobo-Caso MA, Díaz-Martín L, Jiménez-Sosa
A, González-Rinne F, Torres A, Porrini E (2020) The estimation of GFR and the adjustment for BSA in overweight and obesity: a dreadful combination of two errors. Int J Obes (Lond) 44:1129-1140

3. den Bakker E, Gemke R, Bokenkamp A (2018) Endogenous markers for kidney function in children: a review. Crit Rev Clin Lab Sci 55:163-183

4. Ebert N, Bevc S, Bökenkamp A, Gaillard F, Hornum M, Jager KJ, Mariat C, Eriksen BO, Palsson R, Rule AD, van Londen M, White C, Schaeffner E (2021) Assessment of kidney function: clinical indications for measured GFR. Clin Kidney J 14:1861-1870

5. Wyss M, Kaddurah-Daouk R (2000) Creatine and creatinine metabolism. Physiol Rev 80:1107-1213

6. Schloerb PR (1960) Total body water distribution of creatinine and urea in nephrectomized dogs. Am J Physiol 199:661-665

7. Baxmann AC, Ahmed MS, Marques NC, Menon VB, Pereira AB, Kirsztajn GM, Heilberg IP (2008) Influence of muscle mass and physical activity on serum and urinary creatinine and serum cystatin C. Clin J Am Soc Nephrol 3:348-354

8. Schwartz GJ, Work DF (2009) Measurement and estimation of GFR in children and adolescents. Clin J Am Soc Nephrol 4:1832-1843

9. Piepsz A, Tondeur M, Ham H (2006) Revisiting normal (51)Crethylenediaminetetraacetic acid clearance values in children. Eur J Nucl Med Mol Imaging 33:1477-1482

10. Piepsz A, Tondeur M, Ham H (2008) Escaping the correction for body surface area when calculating glomerular filtration rate in children. Eur J Nucl Med Mol Imaging 35:1669-1672

11. Pottel H, Mottaghy FM, Zaman Z, Martens F (2010) On the relationship between glomerular filtration rate and serum creatinine in children. Pediatr Nephrol 25:927-934

12. Delanaye P, Radermecker RP, Rorive M, Depas G, Krzesinski JM (2005) Indexing glomerular filtration rate for body surface area in obese patients is misleading: concept and example. Nephrol Dial Transplant 20:2024-2028

13. Chang AR, Zafar W, Grams ME (2018) Kidney function in obesity-challenges in indexing and estimation. Adv Chronic Kidney Dis 25:31-40

14. D'Agati VD, Chagnac A, de Vries AP, Levi M, Porrini E, HermanEdelstein M, Praga M (2016) Obesity-related glomerulopathy: clinical and pathologic characteristics and pathogenesis. Nat Rev Nephrol 12:453-471

15. Jadresic L, Silverwood RJ, Kinra S, Nitsch D (2019) Can childhood obesity influence later chronic kidney disease? Pediatr Nephrol 34:2457-2477

16. van Dam M, Rijks J, Dorenbos E, Horuz F, van Dael K, Vreugdenhil A (2019) The effect of one year lifestyle intervention on eGFR in children and adolescents with overweight, obesity and morbid obesity. Sci Rep 9:4504

17. Cole TJ, Lobstein T (2012) Extended international (IOTF) body mass index cut-offs for thinness, overweight and obesity. Pediatr Obes 7:284-294

18. Haycock GB, Schwartz GJ, Wisotsky DH (1978) Geometric method for measuring body surface area: a height-weight formula validated in infants, children, and adults. J Pediatr 93:62-66

19. Pottel H, Vrydags N, Mahieu B, Vandewynckele E, Croes K, Martens F (2008) Establishing age/sex related serum creatinine reference intervals from hospital laboratory data based on different statistical methods. Clin Chim Acta 396:49-55

20. Hoste L, Dubourg L, Selistre L, De Souza VC, Ranchin B, HadjAïssa A, Cochat P, Martens F, Pottel H (2014) A new equation to estimate the glomerular filtration rate in children, adolescents and young adults. Nephrol Dial Transplant 29:1082-1091

21. Pottel H, Hoste L, Delanaye P (2015) Abnormal glomerular filtration rate in children, adolescents and young adults starts below 75 $\mathrm{mL} / \mathrm{min} / 1.73 \mathrm{~m}(2)$. Pediatr Nephrol 30:821-828 
22. Pottel H, Hoste L, Martens F (2012) A simple height-independent equation for estimating glomerular filtration rate in children. Pediatr Nephrol 27:973-979

23. Pottel H, Björk J, Courbebaisse M, Couzi L, Ebert N, Eriksen BO, Dalton RN, Dubourg L, Gaillard F, Garrouste C, Grubb A, Jacquemont L, Hansson M, Kamar N, Lamb EJ, Legendre C, Littmann K, Mariat C, Melsom T, Rostaing L, Rule AD, Schaeffner E, Sundin PO, Turner S, Bökenkamp A, Berg U, Åsling-Monemi K, Selistre L, Åkesson A, Larsson A, Nyman U, Delanaye P (2021) Development and validation of a modified full age spectrum creatinine-based equation to estimate glomerular filtration rate : a cross-sectional analysis of pooled data. Ann Intern Med 174:183-191

24. Schwartz GJ, Munoz A, Schneider MF, Mak RH, Kaskel F, Warady BA, Furth SL (2009) New equations to estimate GFR in children with CKD. J Am Soc Nephrol 20:629-637

25. Selistre L, De Souza V, Cochat P, Antonello IC, Hadj-Aissa A, Ranchin B, Dolomanova O, Varennes A, Beyerle F, Bacchetta J, Dubourg L (2012) GFR estimation in adolescents and young adults. J Am Soc Nephrol 23:989-996

26. Pierce CB, Muñoz A, Ng DK, Warady BA, Furth SL, Schwartz GJ (2021) Age- and sex-dependent clinical equations to estimate glomerular filtration rates in children and young adults with chronic kidney disease. Kidney Int 99:948-956

27. Björk J, Nyman U, Delanaye P, Grubb A, Larsson A, Vranken L, Akesson A, Pottel H (2020) A novel method for creatinine adjustment makes the revised Lund-Malmö GFR estimating equation applicable in children. Scand J Clin Lab Invest 80:456-463

28. Björk J, Nyman U, Larsson A, Delanaye P, Pottel H (2021) Estimation of the glomerular filtration rate in children and young adults by means of the CKD-EPI equation with age-adjusted creatinine values. Kidney Int 99:940-947

29. Dart AB, McGavock J, Sharma A, Chateau D, Schwartz GJ, BlydtHansen T (2019) Estimating glomerular filtration rate in youth with obesity and type 2 diabetes: the iCARE study equation. Pediatr Nephrol 34:1565-1574

30. Ceriotti F, Boyd JC, Klein G, Henny J, Queraltó J, Kairisto V, Panteghini M (2008) Reference intervals for serum creatinine concentrations: assessment of available data for global application. Clin Chem 54:559-566

31. Wells JC, Fewtrell MS, Williams JE, Haroun D, Lawson MS, Cole TJ (2006) Body composition in normal weight, overweight and obese children: matched case-control analyses of total and regional tissue masses, and body composition trends in relation to relative weight. Int J Obes (Lond) 30:1506-1513

32. Bostan Gayret Ö, Taşdemir M, Erol M, Tekin Nacaroğlu H, Zengi O, Yiğit Ö (2018) Are there any new reliable markers to detect renal injury in obese children? Ren Fail 40:416-422
33. Önerli Salman D, Şıklar Z, Çullas İlarslan EN, Özçakar ZB, Kocaay P, Berberoğlu M (2019) Evaluation of renal function in obese children and adolescents using serum cystatin C levels, estimated glomerular filtration rate formulae and proteinuria: which is most useful? J Clin Res Pediatr Endocrinol 11:46-54

34. Martin-Del-Campo F, Batis-Ruvalcaba C, Ordaz-Medina SM, Martínez-Ramírez HR, Vizmanos-Lamotte B, Romero-Velarde E, Cortes-Sanabria L, Cueto-Manzano AM (2019) Frequency and risk factors of kidney alterations in children and adolescents who are overweight and obese in a primary health-care setting. J Ren Nutr 29:370-376

35. Murphy MO, Huang H, Bauer JA, Schadler A, Makhoul M, Clasey JL, Chishti AS, Kiessling SG (2021) Impact of pediatric obesity on diurnal blood pressure assessment and cardiovascular risk markers. Front Pediatr 9:596142

36. Correia-Costa L, Schaefer F, Afonso AC, Bustorff M, Guimarães JT, Guerra A, Barros H, Azevedo A (2016) Normalization of glomerular filtration rate in obese children. Pediatr Nephrol 31:1321-1328

37. Morato M, Correia-Costa L, Sousa T, Cosme D, Schaefer F, Areias JC, Guerra A, Afonso AC, Barros H, Azevedo A, AlbinoTeixeira A (2017) Longer duration of obesity is associated with a reduction in urinary angiotensinogen in prepubertal children. Pediatr Nephrol 32:1411-1422

38. Bökenkamp A, Domanetzki M, Zinck R, Schumann G, Brodehl J (1998) Reference values for cystatin C serum concentrations in children. Pediatr Nephrol 12:125-129

39. Dedual MA, Wueest S, Challa TD, Lucchini FC, Aeppli TRJ, Borsigova M, Mauracher AA, Vavassori S, Pachlopnik Schmid J, Blüher M, Konrad D (2020) Obesity-induced increase in cystatin C alleviates tissue inflammation. Diabetes 69:1927-1935

40. den Bakker E, Gemke R, van Wijk JAE, Hubeek I, Stoffel-Wagner B, Bökenkamp A (2018) Combining GFR estimates from cystatin $\mathrm{C}$ and creatinine-what is the optimal mix? Pediatr Nephrol 33:1553-1563

41. Delanaye P, Krzesinski JM (2011) Indexing of renal function parameters by body surface area: intelligence or folly? Nephron Clin Pract 119:c289-c292

Publisher's note Springer Nature remains neutral with regard to jurisdictional claims in published maps and institutional affiliations. 